Portland State University

PDXScholar

12-10-1992

\title{
The Morphology of Lava Flows in Planetary Environments: Predictions From Analog Experiments
}

\author{
Ross W. Griffiths \\ Australian National University \\ Jonathan H. Fink \\ Portland State University, jon.fink@pdx.edu
}

Follow this and additional works at: https://pdxscholar.library.pdx.edu/geology_fac

Part of the Geology Commons, and the Volcanology Commons

Let us know how access to this document benefits you.

\section{Citation Details}

Griffiths, R. W., \& Fink, J. H. (1992). The morphology of lava flows in planetary environments: Predictions from analog experiments. Journal of Geophysical Research: Solid Earth (1978-2012), 97(B13), 19739-19748. 


\title{
The Morphology of Lava Flows in Planetary Environments: Predictions From Analog Experiments
}

\author{
Ross W. GRIFFITHS \\ Research School of Earth Sciences, Australian National University, Canberra
}

JONATHAN H. FINK ${ }^{1}$

Geology Department, Arizona State University, Tempe

\begin{abstract}
The rates of surface cooling and lateral spreading are evaluated for lava flows on the surface of Earth, Venus, Mars, the Moon, and Io. Differences between the flow morphologies expected in these environments are then predicted under the assumption that the results of recent laboratory simulations of lavas using wax extruded beneath cold water (Fink and Griffiths, 1990) can be carried over. These experiments involved the spreading of viscous liquid under gravity in the presence of a solidifying surface crust and revealed a set of four distinct surface morphologies. Transitions from one morphology to the next occurred in a well-defined sequence when the relative rates of surface solidification and lateral spreading were varied. In comparison with subaerial flows on Earth, the surface of lavas solidifies faster on Venus, where the dense atmosphere provides additional convective heat transfer. Lateral flow of lava is much slower under the smaller gravity of the Moon. Hence, for a given extrusion rate and viscosity, solid crust is predicted to form closer to the vent on both the Moon and Venus than on Earth. Equivalently, faster extrusion rates than those on Earth are required on the Moon, Io, and Venus in order to produce a given surface morphology. A comparison of observed structure, flow rates, and estimated viscosities for some well-documented terrestrial lava flows shows reasonable agreement with the predictions of the model. Extrapolation to extraterrestrial lavas is then illustrated by constraining the effusion rate for a Martian lava flow whose composition is assumed. Spectral information on the chemical composition of Martian flows to be sought by the thermal emission spectrometer on the Mars Observer mission, in conjunction with detailed morphologic observations from the Mars Observer camera, could allow much more accurate estimates of effusion rates for Martian lavas.
\end{abstract}

\section{INTRODUCTION}

Terrestrial lava flows are traditionally characterized on the basis of their surface appearance, the behavior of the flow front, and the overall extent of the flow. Pillow basalts, ropy pahoehoe, pressure idges, and marginal levees are all terms referring to structural features of the solidified surface layer. Reoccurrence of each characteristic surface appearance on different lava flows naturally suggests a common set of emplacement conditions, such as a similar thermal history, flow velocity, composition, and melt rheology [e.g., Hulme, 1974; Fink and Fletcher, 1978; Fink, 1980]. Thus the measured composition, extent, and surface structure of a flow can sometimes be used to infer eruption rates of prehistoric lava flows [Pinkerton, 1987]. Surface morphology and eruption rates estimated from observations made during periods of activity are also used to broadly infer the composition of flows on other planets [e.g., Hulme, 1976]. However, such inferences of flow conditions are as yet based only on "rules of thumb" developed from terrestrial experience; to date there has been no clear understanding of the factors affecting surface morphology and the conditions under which each of the observed morphological features will arise.

Results of recent studies point to the possibility of placing the relationship between surface structure and emplacement conditions on a more quantitative, if still empirical, footing. In a series of

'Also at National Science Foundation, Washington, D.C.

Copyright 1992 by the American Geophysical Union.

Paper number 92JB01953.

0148-0227/92/92JB-01953\$05.00 laboratory analog experiments in which polyethylene glycol wax solidified as it spread under cold water, Fink and Griffiths [1990, 1992] observed many of the common surface features found on lava flows: pillows, transverse folds, marginal levees, and an intermediate regime consisting of large rafts of smooth solid crust separated by "rift"-like zones of flow divergence. These four dominant morphologic features, which are typical of those found on relatively short-lived or simple lava flows, are illustrated in the photographs of Figure 1. Each feature formed under a limited set of thermal and dynamic conditions, and to a large extent the conditions giving rise to one structure were exclusive to those giving rise to others. For the most part, the surface morphology in the experiments was dependent only on the relative rates of surface solidification and lateral flow. Only small variations in the conditions at which morphological transitions occurred were found when the base was roughened by addition of coarse wire mesh or inclined up to $6^{\circ}$ from the horizontal. Largely similar behavior was found for radial spreading from a point source and for flow in two directions from a narrow slit (or line) source.

The most immediate extrapolation of the experimental results is to submarine eruptions, since in both cases the cooling is due to a dominant convective heat flux. Griffiths and Fink [1992] show that the rapid quenching of lava by seawater places this system, under a wide range of extrusion rates, in a regime similar to that achieved in wax experiments with the coldest water, most rapid solidification of the wax, and slowest extrusion rates. These are the conditions under which spreading of the wax was through small bulbous outgrowths from the flow front and upper surface. Thus the common occurrence of submarine pillow basalts is consistent with the laboratory results. At the other extreme of submarine flow conditions, rapid extrusions of high-temperature, low-viscosity basalts and komatiites are pre- 

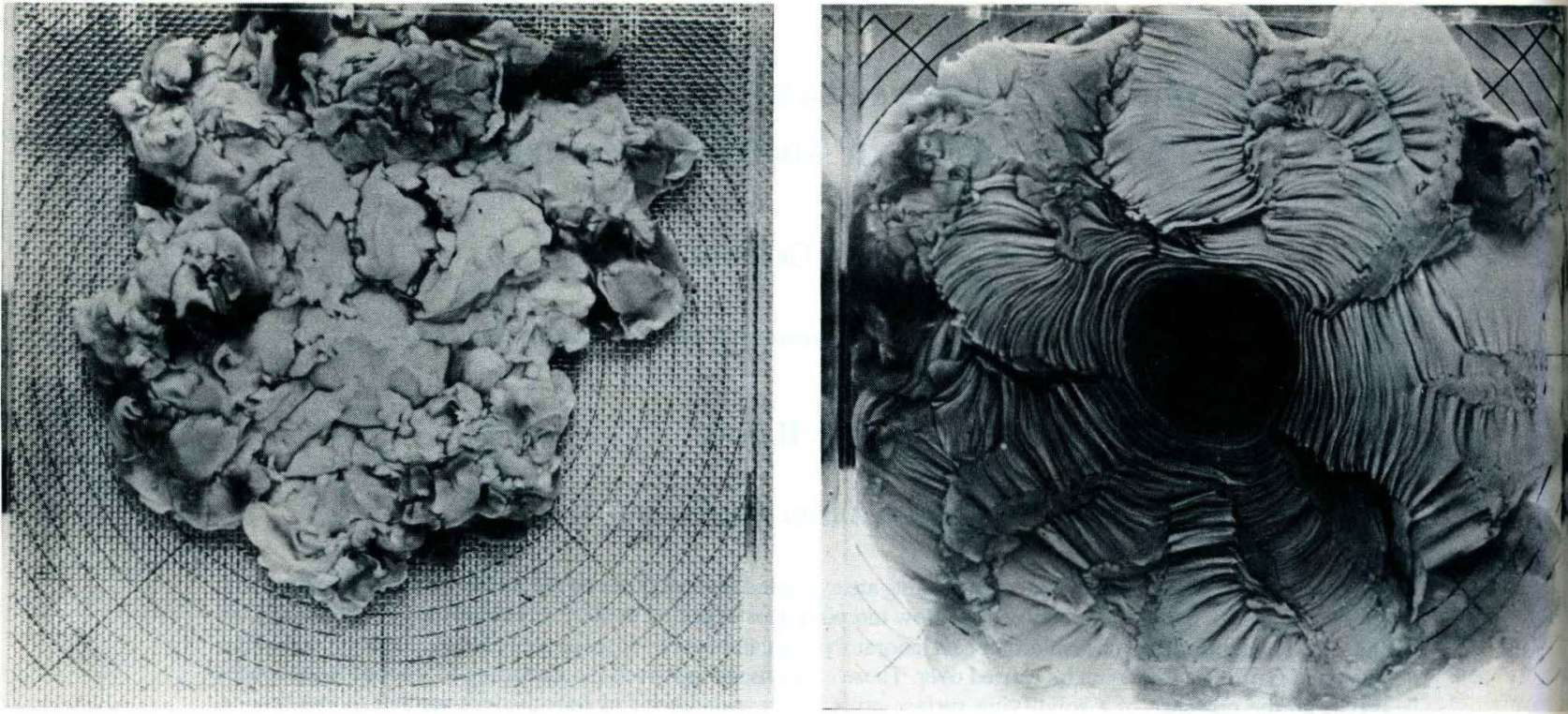

a

C
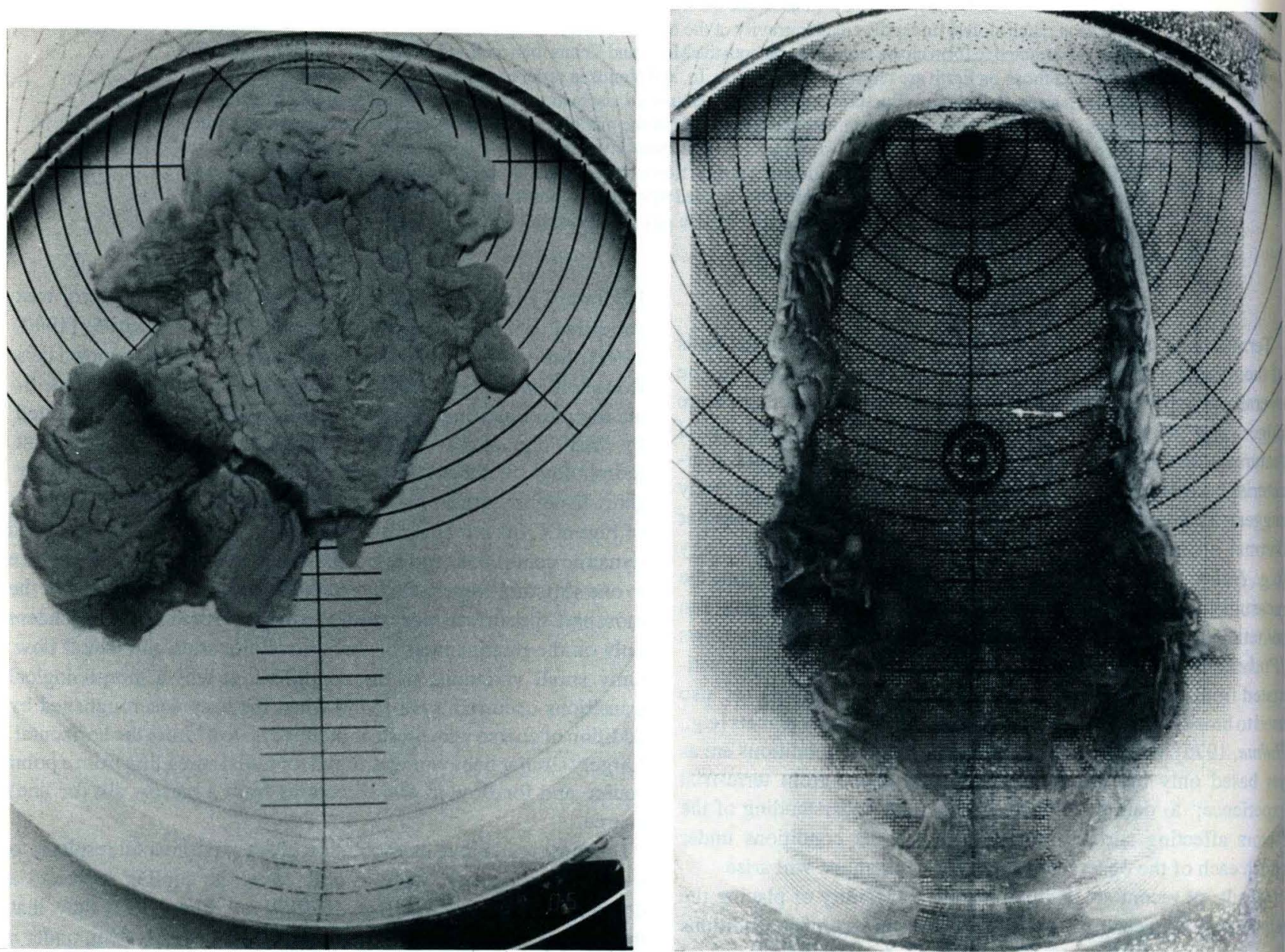

b

d

Fig. 1. Photographs of four flow regimes observed in experiments with polyethylene glycol wax injected onto the bottom of a container of cold sugar solution [from Fink and Griffiths, 1990, 1992]: (a) under rapid cooling the solidified crust forms bulbous protrusions referred to as "pillows" (tank has flat rough base; $\Psi=0.5$, where $\Psi$ is a dimensionless solidification time (see text)); (b) when cooling is not so rapid the crust forms large solid plates which rift away from each other as the viscous melt spreads (sloping smooth base; $\Psi=5$ ); (c) for slower cooling thin crust forms far from the vent and deforms, producing transverse folds (flat smooth base; $\Psi=14$ ); (d) when cooling is slow or extrusion is rapid, crust develops only near the flow front and forms levees (sloping rough base; $\Psi=22$ ). Circles inscribed on bases of tanks are spaced $2 \mathrm{~cm}$ apart. 
dicted to develop levees and no significant amount of crust on the sufface behind the flow front. This prediction is consistent with xtremely smooth, flat surfaces found on submarine lava lakes, some mid-ocean ridge flows, and some submarine Archaean komatiite lows [Arndt et al., 1977].

Environments encountered by lavas extruded onto the surfaces of terrestrial planets and the outer planet satellites are very different from the submarine conditions. Heat fluxes from subaerial lava sufaces are dominated by radiation, although convection is significant under the relatively dense atmosphere of Venus [Wilson and Head, 1983; Head and Wilson, 1986; also see below]. The lateral flow of lavas is also driven by different gravitational forces on each moon or planet. Here we compute the rates of surface cooling and lateral flow for lavas in these various environments and determine the likely flow morphologies predicted by extrapolation of the laboratory analog results. Results of this approach are presented for Earth, Venus, Mars, the Moon, and silicate flows on Io. The predictions, in particular those for subaerial flows on Earth, are intended to serve as a point for comparison with observations where sufficient data exist or can be gathered, but they may also prove useful in constraining magma properties and the dynamics of flow on the other planetary bodies.

\section{Radiative and Convective Heat Fluxes}

The development of crust on the surface of lava flows is controlled by the heat flux from the surface: large fluxes imply more rapid cooling of the surface, appearance of solid crust closer to the vent (or tolocations where melt upwells and becomes exposed to the environment), and a greater thickness of crust at a given distance from the vent. Radiative, convective, and conductive heat transport all occur but in varying proportions according to the temperature of the lava surface and the temperature and physical properties of the environment. Conduction of heat is primarily important within the lava but also plays a role in driving thermal convection in the overlying atmosphere or water. Head and Wilson [1986] found that the estimated fluxes are predominantly radiative during the early stages of cooling of lavas on Earth and Venus but that convective fluxes significantly increase the cooling rate on Venus relative to that on Earth.

The contributions to the heat flux are conveniently summarized by plotting radiative and convective fluxes as functions of the lava surface temperature (Figure 2). For these calculations we have assumed a radiative flux given by Stefan's law

$$
F_{r}=\varepsilon \sigma\left(T_{c}^{4}-T_{a}^{4}\right),
$$

and a turbulent convective flux given by the well-established relation

$$
F_{c}=J\left(T_{c}-T_{a}\right)^{4 / 3}, \quad J=\rho_{a} c_{a} \gamma\left(g \alpha_{a} \kappa_{a}{ }^{2} / v_{a}\right)^{1 / 3},
$$

where $\sigma$ is Boltzmann's constant, $\varepsilon$ is the emissivity of the surface (assumed to be 0.9 in all cases); $T_{c}$ is the lava surface (or contact) temperature, $T_{a}$ is the ambient temperature, $\rho_{a}, c_{a}, \alpha_{a}, \kappa_{a}$, and $v_{a}$ are the density, specific heat, thermal expansion coefficient, thermal diffusivity, and kinematic viscosity, respectively, of the environment, and $\gamma$ is a constant whose value is approximately 0.1 [Turner, 1973, p. 215; Huppert and Sparks, 1988]. The convective flux (2) includes only that due to buoyancy-driven motion in the absence of forced convection (winds), because the heat fluxes due to winds are highly variable and in any case will generally be much less than the bioyancy-driven fluxes during the early stages of cooling [ Head and Wilson, 1986]. No allowance is made for latent heat effects in "wet" atmospheres, where latent heat of evaporation may add to the heat loss. The corresponding fluxes computed for the case of submarine

\section{Heat fluxes from lava surfaces}

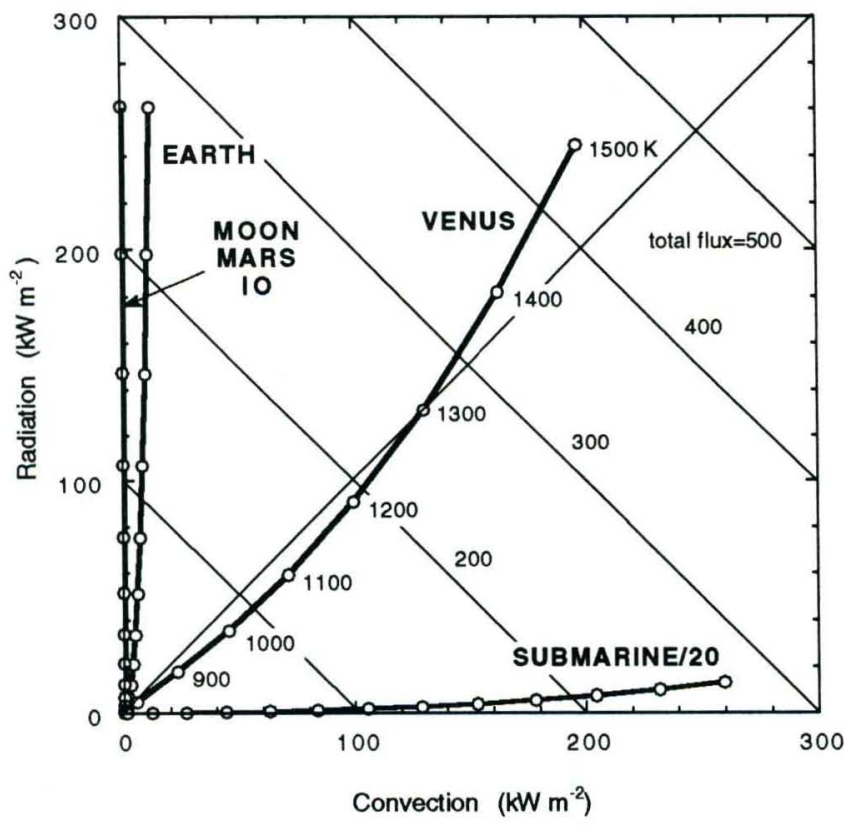

Fig. 2. Calculated radiative and convective fluxes from lava surfaces as functions of the surface temperature (intervals of $100 \mathrm{~K}$, up to $1500 \mathrm{~K}$, are shown by circles). The total flux is contoured by oblique lines at intervals of $100 \mathrm{~kW} \mathrm{~m}^{-2}$. Fluxes for submarine surfaces [from Griffiths and Fink, 1992] are divided by 20 for convenience of plotting. Fluxes for Mars and Io are identical to those for the Moon.

eruptions [Griffiths and Fink, 1992] are shown in Figure 2 for comparison.

The values of physical parameters for each environment are listed in Table 1. In estimating convective fluxes the expansion coefficient and environment viscosity are evaluated not for the ambient conditions but for an estimated average temperature to be encountered in the atmospheric thermal boundary layer above the lava surface. This is because the duration of any single eruption is extremely short compared with the time that would be required to heat the whole of the surrounding atmosphere (or ocean). Hence heat transport in the environment is highly unsteady, transport of heat far from the surface is not required, and convective transport is driven by the buoyancy in the boundary layers rather than that in the interior of the convecting environment [Griffiths and Fink, 1992]. Thus the expansion coefficient used for seawater was taken from measured densities of seawater at pressures corresponding to water depths of $1000-4000 \mathrm{~m}$ and temperatures of order $600 \mathrm{~K}\left(300-400^{\circ} \mathrm{C}\right)$, a rough average of the boundary layer temperatures expected close to lava vents. The expansion coefficient for atmospheres is obtained from the ideal gas result ( $\alpha=T^{-1}$, where $T$ is in kelvins) and by taking an average across the boundary layer: $\alpha_{a} \approx(1 / 2)\left(T_{a}^{-1}+T_{c}^{-1}\right)$. The background radiation temperature for the Moon and Io is taken to be that for space ( $3 \mathbf{K})$; that for Mars is taken to be the ambient atmospheric temperature of $240 \mathrm{~K}$ [Kiefferet al., 1977], although this value does not significantly alter the calculated heat fluxes or cooling times. Direct solar radiation does not significantly alter the net radiative flux from flows on the sunlit side of these bodies. The calculated fluxes in Figure 2 are consistent with those of Head and Wilson [1986], although our radiative fluxes are very slightly larger (as a result of a larger value assumed for the emissivity) and convective fluxes on Venus are slightly larger, probably as a result of a different value for $\alpha_{a}$.

The main conclusion to be drawn from Figure 2 is that the initial stages of cooling on Earth, the Moon, Mars and Io are dominated by 
TABLE 1. Values of Parameters Used in Calculations for Each Planetary Environment

\begin{tabular}{llllll}
\hline Parameter & Earth & Venus & Mars & Moon & Io \\
\hline$g, \mathrm{~m} \mathrm{~s}^{-2}$ & 9.8 & 8.8 & 3.76 & 1.6 & 1.8 \\
$T_{a}, \mathrm{~K}$ & 290 & 750 & 240 & 3 & 3 \\
$\rho_{a}, \mathrm{~kg} \mathrm{~m}^{-3}$ & 1.2 & 65 & 0.02 & 0 & 0 \\
$\mathrm{v}_{a}, \mathrm{~m}^{2} \mathrm{~s}^{-1}$ & $1.3 \times 10^{-5}$ & $1 \times 10^{-5}$ & & \\
$\eta_{a}, \mathrm{~Pa} \mathrm{~s}^{2}$ & $1.6 \times 10^{-5}$ & $6.5 \times 10^{-4}$ & & \\
$\kappa_{a}, \mathrm{~m}^{2} \mathrm{~s}^{-1}$ & $1.9 \times 10^{-5}$ & $1 \times 10^{-5}$ & & \\
$c_{a}, \mathrm{~J} \mathrm{~kg}^{-1} \mathrm{~K}^{-1}$ & 1005 & $1 \times 10^{3}$ & & \\
$\alpha_{a}, \mathrm{~K}^{-1}$ & $2 \times 10^{-3}$ & $1 \times 10^{-3}$ & & & \\
\hline
\end{tabular}

Symbols are defined in the text. Ambient temperatures $T_{a}$ are the radiative temperatures of the atmosphere or space; the value used for Venus is appropriate for lowland areas on that planet. The specific heat used for Earth's atmosphere is that for dry air. Because the density of the ambient atmosphere is effectively zero for the Moon and Io, and very low for Mars, convective heat transport is negligible to nonexistent. Consequently, most of the ambient properties for these planetary bodies are not relevant.

radiative heat loss (in the figure results for Mars and Io overlay those for the Moon), submarine eruptions are cooled almost entirely by convection (as a result of the large volumetric heat capacity of water), and lavas on Venus are cooled by a combination of the two mechanisms. On Venus the dominant mechanism changes from radiation to convection when the lava surface temperature falls below approximately $1300 \mathrm{~K}$. For a given lava surface temperature the heat flux from submarine lavas is some 20 times greater than that from subaerial flows on Earth (consequently submarine flux values on Figure 2 are divided by 20 for plotting convenience), whereas the flux from Venusian flows is about 1.6 times greater. Over the range of temperatures shown convection adds less than $20 \%$ to the flux from terrestrial flows. The difference between the ambient radiative temperature on Earth and that on the Moon leads to a negligible difference in radiative flux.

\section{DeVelopment of Solid CRUST}

The differing surface heat fluxes shown in Figure 2 lead to different rates of cooling of the surface temperature $T_{c}$ and different temperature profiles within the lava. The temperature distributions in the lava are found by solving numerically a standard integral equation [Carslaw and Jaeger, 1959, p. 76] describing the temperature in a half-space $\mathrm{z} \geq 0$ initially at uniform temperature $T_{l}$ and cooled as a result of a heat flux $F(t)$ from its surface at $z=0$. In the present case the flux $F$ is the sum of the radiative and convective fluxes (1) and (2). Since the ambient temperature $T_{a}$ can safely be assumed constant in time, $F$ is a function only of the contact temperature $T_{c}=T(z=0)$, which decreases in time. The integral equation can be transformed into

$$
T(z, t)-T_{l}=\frac{-1}{\rho c(\kappa \pi)} \int_{0}^{t} F(\lambda) e^{-x^{2} / 4 \kappa(t-\lambda)} \frac{d \lambda}{\sqrt{t-\lambda}}
$$

(where $\kappa$ is thermal diffusivity of the lava and $\lambda$ is a dummy variable), and solutions can be computed using the product integral technique. Solutions to (3) were checked by comparison with asymptotic approximations valid for $T_{l}-T \ll T_{l}-T_{a}$ (that is, at small times after cooling commences) obtained by linearizing the boundary fluxes (1) and (2) and applying standard techniques: for a convective flux alone

$$
\frac{T_{c}-T_{a}}{T_{l}-T_{a}} \approx \frac{1}{4}+\frac{3}{4} e^{t / \lambda_{c}} \operatorname{erfc}\left(\frac{t}{\lambda_{c}}\right)^{1 / 2},
$$

where $\lambda_{c}=(9 / 16 \pi)\left(\rho c / \rho_{a} c_{a}\right)^{2}\left(\pi / \gamma^{2}\right)\left[v_{a} / g \alpha_{a}\left(\mathrm{~T}_{l}-\mathrm{T}_{a}\right)\right]^{2 / 3} \kappa \kappa_{a}^{-4 / 3}$ is the time scale; and for a radiative flux alone

$$
\frac{T_{c}-T_{a}}{T_{l}-T_{a}} \approx \frac{\left(T_{l}^{4}-T_{a}^{4}\right)}{4 T_{l}^{3}\left(T_{l}-T_{a}\right)}\left[1-e^{t / \lambda_{r}} \operatorname{erfc}\left(\frac{t}{\lambda_{c}}\right)^{1 / 2}\right],
$$

where the time scale is $\lambda_{r}=\left(\rho c / 4 \varepsilon \sigma T_{l}^{3}\right)^{2} \kappa$. These asymptotic solutions provide good approximations to the numerical solutions of (3) for $T_{c}>1000 \mathrm{~K}$ (for convection) or $T_{c}>1200 \mathrm{~K}$ (radiation) and are therefore useful if the reader wishes to calculate solutions for variable values other than those used in this paper.

Examples of exact solutions of ( 3 ) for $z=0$ and an eruption temperature of $1423 \mathrm{~K}$ (Figure 3 ) show the influence of the radiative and convective fluxes on contact temperatures in each planetary environment. Relevant thermal properties assumed for lava are listed in Table 2. (The corresponding results for submarine extrusions are given byGriffiths and Fink [1992]). Curves showing the contact temperatures on Earth, Mars, the Moon, and Io overlie each other when only radiative fluxes are allowed. Convection leads to an

\section{Contact temperatures}

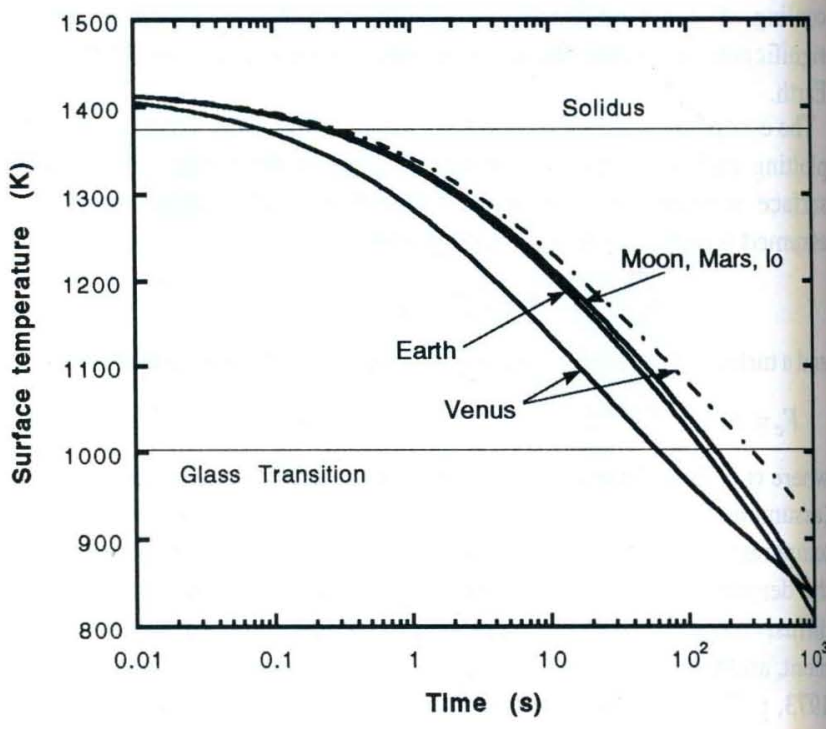

Fig. 3. Evolution of the surface temperature of lavas erupted at $1423 \mathrm{~K}$ on Earth, Venus, Mars, Moon, and Io as functions of the time after exposure of magma to the environment (curves for Mars, Moon, and Io are identical). Results for Venus assuming only radiative heat transfer are shown for reference (dashed curve). Radiation alone from subaerial lavas on Earth gives a curve indistinguishable (on the scale of this graph) from that for the Moon, Io, and Mars. Temperatures at the solidus $(1373 \mathrm{~K})$ and glass transition $(1003 \mathrm{~K})$ for basalt are shown. 
TABLE 2. Magma Properties and Physical Constants

$\begin{array}{cll}\text { Parameter } & \text { Value } & \text { Units } \\ \kappa & 5 \times 10^{-7} & \mathrm{~m}^{2} \mathrm{~s}^{-1} \\ \rho & 2.6 \times 10^{3} & \mathrm{~kg} \mathrm{~m}^{-3} \\ c & 1.2 \times 10^{3} & \mathrm{~J} \mathrm{~kg}^{-1} \mathrm{~K}^{-1} \\ \varepsilon & 0.9 & \text { dimensionless } \\ \sigma & 5.73 \times 10^{-8} & \mathrm{~m}^{-2} \mathrm{~K}^{-4}\end{array}$

Same values are used in all calculations. Symbols are defined in the text. The thermal diffusivity, density, and specific heat are only slightly different for different magma compositions; hence they are fixed in the present calculations in order to concentrate on primary variables.

additional $10 \mathrm{~K}$ of cooling after $100 \mathrm{~s}$ on Earth. Convective fluxes on Venus cause a more significant cooling during the first $100 \mathrm{~s}$. However, after the contact temperature has fallen below about $900 \mathrm{~K}$ the relatively high temperature of the Venus atmosphere leads to a slower rate of cooling than on Earth.

Since the development of crust on the lava surface is of primary concern in predicting flow morphology, a temperature of effective solidification is required. A nominal value for the temperature at the solidus for basalts can be taken as $1373 \mathrm{~K}\left(1100^{\circ} \mathrm{C}\right)$ [Turcotte and Schubert, 1982, p. 144]. However, this is the temperature below which no melt will exist under equilibrium conditions, whereas the chilled outer surface of a lava is far from equilibrium. The kinetics of crystallization on cooling slow the process to such an extent that no significant degree of crystallization can occur very close to the rapidly cooled contact surface. Laboratory constructions of temperature-time-transformation curves for a number of lunar basalt samples cooled from their liquidus show that a volume fraction of crystals as small as $10^{-6}$ forms only after a minimum time of order $10^{3}-10^{4} \mathrm{~s}$ and then only if the sample has not cooled below temperatures of around $1100 \mathrm{~K}$ in this time [e.g., Uhlmann and Klein, 1976; Uhlmann et al., 1979]. More rapid cooling to lower temperatures leads only to formation of glass. The glass transition temperature is estimated to be approximately $1003 \pm 15 \mathrm{~K}\left(730^{\circ} \mathrm{C}\right)$ for basalts [Ryan and Sammis, 1981] and about $670^{\circ} \mathrm{C}$ for rhyolite lavas [Westrich et al., 1988]. For subarial conditions on Earth (Figure 3) the contact surface first passes through the solidus at approximately $0.4 \mathrm{~s}$ after the fluid magma is exposed and through the basalt glass transition at approximately $125 \mathrm{~s}$. Hence the surface will be a solid glass long before crystallization becomes significant at any depth in the lava. Because we are most interested in the morphology of the flow surface rather than the overall flow dimensions, we neglect latent heat effects in the heat flow solutions. Existence of a small fraction of crystals in the magma issuing from the vent will reduce the time taken for a given volume fraction of crystals to form but does not increase the growth rate of crystal surfaces [Kirkpatrick, 1981] and therefore does not reduce the crystallization time by orders of magnitude. A major increase in the amount of crystals in the solid lava at the surface, sufficient to significantly reduce the time required to form an effectively solid crust, could result only from very large fractions (perhaps greater than 50\%) of preexisting crystals. Therefore, although this situation is relevant to some relatively low temperature lavas, the appropriate surface solidification temperature $T_{s}$ will generally be that of the glass transition.

For basalts the times $t_{s}$ required for commencement of surface solidification on flows erupted at $1423 \mathrm{~K}$ are 151 s on the Moon, $140 \mathrm{~s}$ on Mars, 125 s on Earth, and 57 s on Venus. In contrast, Griffiths and Fink [1992] found the much smaller time $t_{s} \approx 0.07 \mathrm{~s}$ for submarine lavas having the same vent temperature. The dependence of $t_{s}$ on vent temperature is shown in Figure 4: for vent temperatures in the range
Solidification times

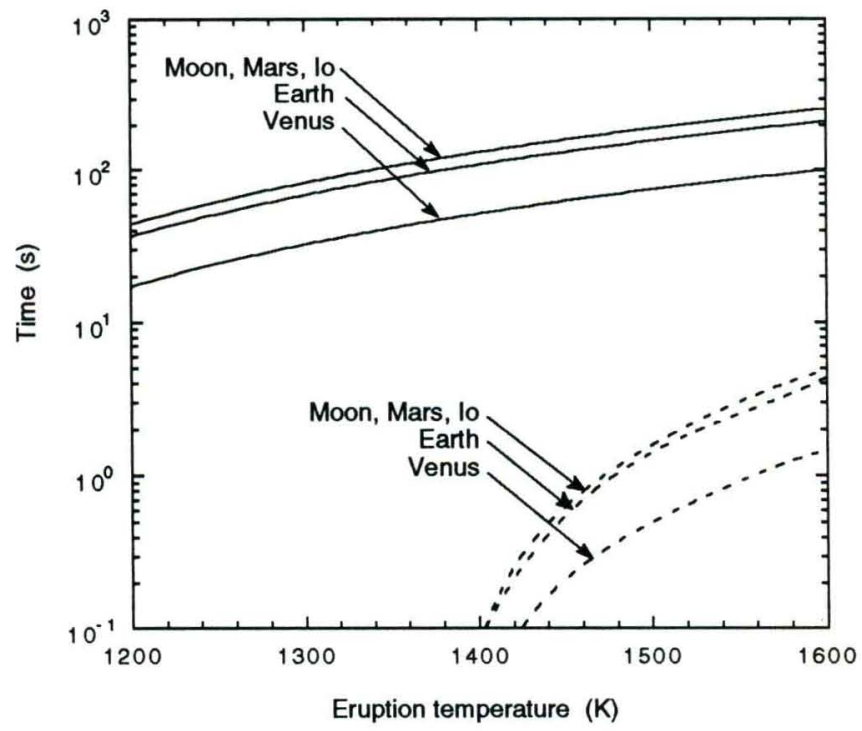

Fig. 4. Times for the surface of magma erupted into various environments to pass through $1373 \mathrm{~K}$ (dashed curves) and $1003 \mathrm{~K}$ (solid curves) as functions of magma temperature at the vent. The temperature of $1003 \mathrm{~K}$ is taken as the glass transition for basalt and is the relevant solidification temperature, whereas $1373 \mathrm{~K}$ is a nominal temperature for the solidus and is shown here only for reference. Results for Io and Mars are identical to those for the Moon.

$1300-1500 \mathrm{~K}$ (or $1000-1200^{\circ} \mathrm{C}$ ) the solidification times for each of the four environments vary by no more than a factor of 2 .

Depths of isotherms are illustrated in Figure 5, where we trace through time the position of the solidus (assumed to be at $1373 \mathrm{~K}$ ), the glass transition $(1003 \mathrm{~K})$, and an intermediate isotherm at 1200 $\mathrm{K}$, all for the case of a basalt erupted at $1423 \mathrm{~K}\left(1150^{\circ} \mathrm{C}\right)$ on the surface of the Earth. After $1000 \mathrm{~s}$ of cooling, the vitrified crust will be $4 \mathrm{~mm}$ thick. At $t>1000 \mathrm{~s}$ the depths of all three isotherms asymptote to the simple $t^{1 / 2}$ law, and at $t=10^{4} \mathrm{~s}$ the crust is nearly 2 $\mathrm{cm}$ thick. At $t \gg 1000 \mathrm{~s}$, crystallization may begin to reach significant volume fractions at depths below the glassy crust. Thus large crystal fractions are predicted to appear only at depths greater than a

\section{Isotherm depths: Earth}

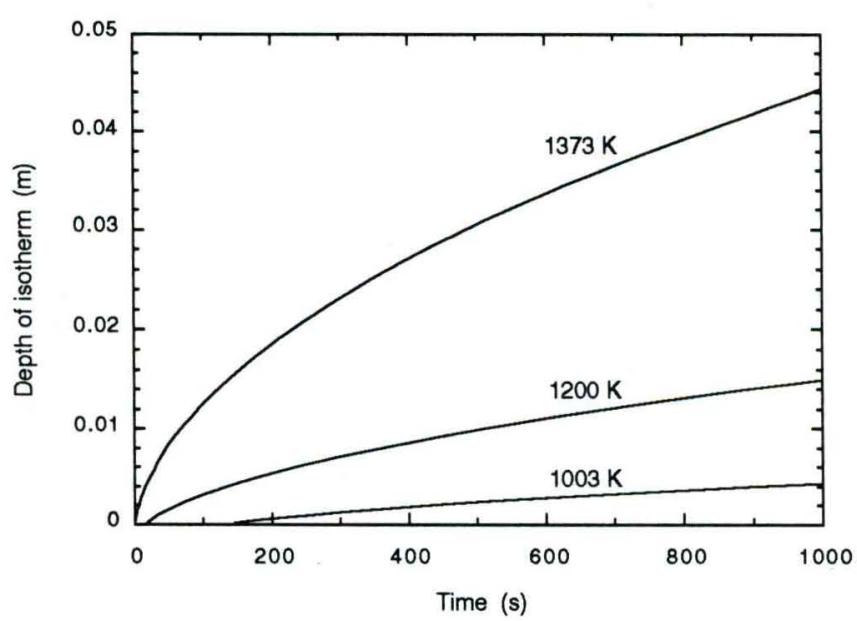

Fig. 5. Depths below the lava surface of three isotherms as functions of time after exposure to the terrestrial atmosphere. Vent temperature is $1423 \mathrm{~K}$. The shallowest isotherm shown corresponds to the glass transition, hence the relevant solidification temperature. 
few centimeters. This estimate is consistent with the existence of glassy textures through the top $2-5 \mathrm{~cm}$ of solidified pahoehoe basalts [e.g., Fink and Fletcher, 1978]. Furthermore, if our hypothesis that surface morphology depends primarily on the relative times for crust formation and lateral flow is valid, the transition from a glassy upper crust to a predominantly crystalline solid deeper in the flow will not influence the morphology.

\section{SCALING OF LATERAL FLow}

Fink and Griffiths [1990] suggested that the most relevant parameter determining surface morphology is the ratio of the time $t_{s}$ taken for solid crust to form on an element of lava issuing from a vent to a characteristic time scale $t_{a}$ for horizontal advection of the lava: $\Psi=t_{s} / t_{a}$. Because the wax experiments involve a viscous liquid extruded onto a plane, the reference time for horizontal spreading was chosen as that appropriate for isothermal, isoviscous flow having no crust. For such a flow the depth and velocity scales are

$$
H \sim(\eta Q / g \Delta \rho)^{1 / 4}, \quad U \sim(g \Delta \rho Q / \eta)^{1 / 2}
$$

for a point source (where $Q$ is the volume flux from the vent) and

$$
H \sim(\eta q / g \Delta \rho)^{1 / 3}, \quad U \sim\left(g \Delta \rho q^{2} / \eta\right)^{1 / 3}
$$

for a line source (where $q$ is the volume flux per unit length of the fissure). In (5) and (6), $g$ is the gravitational acceleration $\Delta \rho=\rho-\rho_{a}$ (where $\rho$ is the density of the lava and $\rho_{a}$ is the ambient density of the environment) and $\eta$ is the viscosity of the thermally homogeneous fluid magma in the interior of the flow. The time scale is then $t_{a}=H / U$, which becomes

$$
\begin{array}{ll}
\text { Point source } & t_{a}=(\eta / g \Delta \rho)^{3 / 4} Q^{-1 / 4} \\
\text { Line source } & t_{a}=(\eta / g \Delta \rho)^{2 / 3} q^{-1 / 3}
\end{array}
$$

The time scales (7) are useful in normalizing the flow of crusted lava so long as the interior of the extruded'magma, betore cooling, can be satisfactorily described in terms of an apparent viscosity. Fink and Griffiths [1992] showed that the distance $D_{s}$ from the vent at which the surface begins to solidify is, for the above idealized geometries,

$$
\begin{array}{ll}
\text { Axisymmetric } & D_{s}=H \Psi^{1 / 2}, \\
\text { Line source } & D_{s}=H \Psi .
\end{array}
$$

\section{Morphology of Laboratory and Terrestrial Flows}

The wax experiments showed that major changes in morphology occurred at fixed values of $\Psi$. For $\Psi<3$ (most rapid solidification), spreading took place by irregular bulbous outgrowths, or "pillows", which were much smaller than the whole flow. Some pillows near the flow front broke off after developing a rigid crust and fell, like snails' shells, onto the base, where they were later covered by further pillows. These led to a final flow surface with a lumpy or pillowy structure. For $3<\Psi<10$, surface plates of solid tended to move apart along linear fractures where molten wax upwelled and further solid accreted onto the plates. This was termed a "rifting" regime. In the case of extrusions from a line source there was usually one main rift over the source and two broad smooth plates that moved out away from the fissure. At slower cooling rates or larger extrusion rates, where $10<\Psi<25$, pillows and rifting gave way to a regime in which the crust formed relatively far from the vent and was deformed into transverse folds. These folds sometimes appeared to consist of more than one wavelength and took on the "ropy" structure best known from pahoehoe basalts but common in flows of all compositions. At $\Psi>25$ the crust developed only near the flow front, where it tended to form levee banks. When on a horizontal base, these levees developed along the front and tended to halt its local advance untilthe retained melt deepened and either overflowed the levee or broke through. When on a sloping base, both the surface folds and the levees tended to develop best along the edges of the down-slope flow. forming a channel. Finally, at the largest values of $\Psi$ used in the experiments $(\Psi>55)$ the flow front reached the walls of the container before any significant amount of crust formed. It was not clear whether levees would have eventually developed on these flowsi walls had not been present.

Values of $\Psi$ calculated for subaerial lavas depend on the vent and glass transition temperatures, magma viscosity and extrusion rate Hence we plot in Figure 6 three contours of constant $\Psi$ (correspond ing to the empirical morphologic transitions at $\Psi \approx 3,10$, and 25 ) the flow rate-viscosity plane: these are for Earth conditions and a vent temperature of $1423 \mathrm{~K}$. Lower vent temperatures associated with more silicic compositions would cause the lines of constant $\Psi$ to shift downward and to the right. For instance, if we use a vent temperature of $1173 \mathrm{~K}\left(900^{\circ} \mathrm{C}\right)$ appropriate for rhyolite, then the viscosity intercept of the $\Psi$ contours would decrease by a factor of 8 . However, if we also reduce the glass transition temperature from $1003 \mathrm{~K}$ to 943 $\mathrm{K}$, then the $\Psi$ values shift downward by only a factor of 2 .

In order to see how well the above results apply to terrestrial lava flows, we plot extrusion rates and corresponding magma viscosities for some well-documented eruptions. Some of the extrusion rates shown may be considered maxima because velocities in any given flow will eventually decrease to zero. Similarly, branching causesthe local flow rate in individual channels to drop. However, decreasing flow rates will generally be associated with increases in both cooling rate and viscosity. Hence we expect data for a single lava flow to fall within a vertical or diagonal zone extending upward and to the left across Figure 6 . Source geometry must also be taken into account.lf all of the erupted magma comes from a long fissure, the flux per unit length is more relevant than the total flux, at least during early stages of eruption. Similarly, if a flow becomes fully channelized, the flux per unit width of the channel becomes the appropriate measure. Figure 6 indicates morphologic transitions for eruptions from both point source and linear vents.

The 1984 Mauna Loa basalt flow was exceptionally well-documented. Moore [1987] calculated apparent viscosities ranging from $10^{2}$ to $10^{7} \mathrm{~Pa}$ s based on observed velocities and measured channel dimensions from 10 sites along the flow length. For lava in a confined channel, the apparent viscosity of the bulk flow computed in this manner is comparable to that of the interior fluid, which is used in deriving $\Psi$ (here we omit those viscosity values Moore computed for positions near the flow front where the assumption of channelization does not apply). Lipman and Banks [1987] presented flow rate data collected at roughly the same times and locations as the data of Moore [1987]. Hence we can combine these two data sets to constrain a range of $\Psi$ values likely to have existed in the active flow. Nearly all of these measurements were made on channelized flows confined by levees and thus would be expected to fall below the line $\Psi=25$ (Figure 6).

The 1975 subterminal lava flows at Mount Etna were studied in detail by Pinkerton and Sparks [1976]. They described three different morphologies and associated flow rates: levees $\left(Q>2 \times 10^{-3} \mathrm{~m}^{3}\right)$ ropy tongues (which should correspond to our "folding" regime) $(2 x$ $10^{-3} \mathrm{~m}^{3} \mathrm{~s}^{-1}>Q>5 \times 10^{-4} \mathrm{~m}^{3} \mathrm{~s}^{-1}$ ), and toey pahoehoe (which forms in a manner analogous to submarine pillow basalts $)\left(Q<5 \times 10^{-4} \mathrm{~m}^{3} \mathrm{~s}^{-1}\right)$ If we assume the apparent viscosities of about $10^{4} \mathrm{~Pa}$ s reported by Pinkerton and Sparks [1978] for measurements of the interiors of th same flows, we find that the $\Psi$ values plot near the position predicted by the wax experiments for levees and folds but higher than 


\section{Morphologies of terrestrial flows}

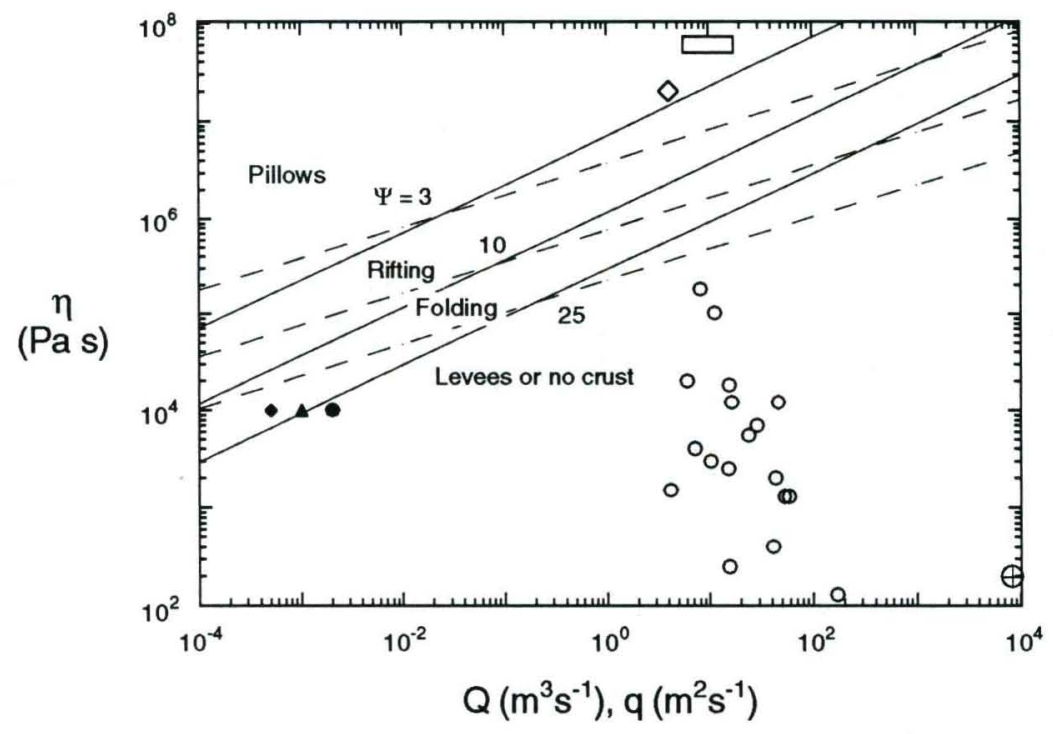

Fig. 6. Contours of constant $\Psi$ (dimensionless solidification time) in terms of extrusion rate and magma viscosity under terrestrial conditions, for point sources (effusion rate $Q$, dashed curves) and line sources (effusion rate $q$, solid curves). The $\Psi$ contours shown are the empirical transitions between morphologic regimes in laboratory wax experiments. Their positions are calculated assuming a vent temperature of $1423 \mathrm{~K}$ and glass transition of $1003 \mathrm{~K}$. The data shown are for open circles, 1984 Mauna Loa basalt flow; solid circle, leveed channels formed on the 1975 basaltic andesite flow from Mount Etna; triangle, ropy tongues on the same Etna flow; solid diamond, slablike tongues and smooth toes on the same Etna flow; open diamond, the blocky but otherwise featureless andesite dome of La Soufriere in 1979; rectangle, range of values calculated for the October 1981 and March, May, and August 1982 lobes of the Mount St. Helens dacite dome; and circled cross, an estimate for Columbia River flood basalt flows. La Soufriere, Mount St. Helens, and Columbia River basalt data are plotted in terms of total volume flow rates $(Q)$, whereas Mauna Loa and Etna data are plotted in terms of flow rate per unit width $(q)$, because the flows are largely one-directional. In the latter cases, $q$ was calculated from published data for total flow rates assuming channel widths of $15 \mathrm{~m}$ for Mauna Loa and $1 \mathrm{~m}$ for the Etna lavas. See text for data sources.

expected for the pillow regime (Figure 6). This discrepancy might be caused by higher viscosities in the pahoehoe toes than those measured by Pinkerton and Sparks [1978].

A closely monitored andesitic dome was emplaced in the crater of La Soufriere of St. Vincent over a 150-day period in 1979 [Huppert et al., 1982]. The dome grew continuously through a process of endogenous inflation coupled with lateral spreading and fracturing of the crust, analogous to the development of a single pillow in one of the coldest wax experiments. The dome had an average eruption rate of about $4 \mathrm{~m}^{3} \mathrm{~s}^{-1}$. If the apparent viscosity of the erupted magma is taken to be $2 \times 10^{7} \mathrm{~Pa} \mathrm{~s}$, the dome lies just within the pillow regime (Figure 6).

Emplacement of the Mount St. Helens dacite dome between 1980 and 1986 was also carefully observed [e.g., Swanson et al., 1987; Chadwick et al., 1988; Swanson and Holcomb, 1990]. The dome grew during more than 15 discrete episodes that combined endogenous inflation and exogenous extrusion. During many of these eruptions, the dome initially stretched and expanded and then cracked near its apex, allowing lava to emerge through a paired set of elongate fractures referred to as crease structures [Anderson and Fink, 1990, 1992]. This style of growth is similar to the pillow behavior observed in the experiments but may also have features in common with flow behavior in the rifting regime: the crease structures might represent the fractures along which fully inflated pillows rupture or, alternatively, they might be better described as rifts at which two solidified surfaces are diverging. Extrusion rates and apparent viscosities for several of the crystal-rich lobes extruded in 1981 and 1982 were calculated by Chadwick et al. [1988]. They found maximum flow rates during extrusion that ranged from 7 to $15 \mathrm{~m}^{3} \mathrm{~s}^{-1}$ and viscosities from $10^{9}$ to $10^{10} \mathrm{~Pa}$. However, apparent viscosities calculated for entire flow lobes include the influence of the cooled surface crust and thus are less appropriate for determining $\Psi$ values than lower interior viscosities. The latter may be calculated as $10^{7} \mathrm{~Pa} s$ using Figures 5 and 6 of Murase et al. [1985], assuming a crystallinity of $40 \%$, water content of 0.5 wt $\%$, and temperature of $980^{\circ} \mathrm{C}$. Combining this viscosity with Chadwick et al.'s [1988] flow rates gives a horizontal line on Figure 6 close to the boundary between the pillow and rifting regions.

These calculations show a rough correspondence between the transitions defined by the wax experiments and those observed in terrestrial lava flows. Additional comparisons can be made for prehistoric flows. Shaw and Swanson [1970] calculated a maximum effusion rate of $10^{6} \mathrm{~m}^{3} \mathrm{~s}^{-1}$ for one of the Columbia River flood basalts. Assuming a viscosity of $100 \mathrm{~Pa}$ s yields a point far into the "no crust" regime. Similarly, some high-temperature komatiitic flows of the Archaean would have had $\Psi>10^{2}$ (assuming $\eta \sim 10^{-1}-10$ Pa s, $Q>10^{3}$ $\mathrm{m}^{3} \mathrm{~s}^{-1}$ ) even though they are inferred to have been submarine eruptions [Arndt et al., 1977]. Although these lavas were probably turbulent, we can say that they would have developed crust (during their active spreading phase) only near the margins of extensive flows, leaving broad smooth surfaces to solidify over much of the lava after spreading velocities decreased. In contrast, Griffiths and Fink [1992] predict that submarine effusion rates of less than $1 \mathrm{~m}^{3} \mathrm{~s}^{-1}$ will produce pillow lavas. Some Archaean flows are found to be capped by extremely smooth, flat surfaces [Arndt et al., 1977], whereas other more mafic komatiites are pillowed [Nisbet et al., 1977].

The experimental results also allow us to use morphology to estimate interior viscosities of flows for which extrusion rates have been observed. We used videotapes made in 1987 of the Puu Oo 
basalt flows to estimate effusion rates of around $10^{-4} \mathrm{~m}^{3} \mathrm{~s}^{-1}$ for several small pahoehoe flows that were undergoing folding. According to Figure 6, these flow rates require that the lava had an interior viscosity of from 1-3 $\times 10^{4} \mathrm{Pas}$. These values are slightly higher than those estimated from laboratory measurements [Shaw, 1969] but not unreasonable for marginal outflows.

A final application of these results involves constraining effusion rates for flows whose viscosities are known or inferred. For ex ample, several large andesite flows on the north flank of Mount Shasta (California) show prominent, regularly spaced surface folds. Using a laboratory-derived viscosity value of $5 \times 10^{4} \mathrm{~Pa} \mathrm{~s}$ at an eruption temperature of $1000^{\circ} \mathrm{C}$ [Murase and MCBirney, 1973] and a flow width of $200 \mathrm{~m}$, Figure 6 gives an eruption rate between 0.4 and $6 \mathrm{~m}^{3}$ $\mathrm{s}^{-1}$. The upper limit of this range is similar to the measured flow rate of $4 \mathrm{~m}^{3} \mathrm{~s}^{-1}$ for the andesitic lava dome of La Soufriere [Huppert et al., 1982].

\section{MORPHOLOGY OP EXTRATERRESTRIAL LAVAS}

A dependence of surface morphology on the time taken for the lava surface to solidify and the rate of lateral spreading has implications for the emplacement conditions of lava flows on Venus, Mars, and the silicate moons of the solar system. The parameter values listed in Table 1 imply that the ratio $\Psi$ of time scales for point sources, given an extrusion temperature, flow rate, and magma viscosity, is $\mathbf{1 . 7}$ times smaller on Mars than on Earth, 2.5 times smaller on Venus, and a factor of 3.3 smaller on the Moon and Io (Figure 7). The differences from lava flows on Earth result primarily from the smaller gravitational forces available to drive lateral flow on Mars and the Moon and the role of convection in causing more rapid cooling of lavas on Venus. Equivalently, each of the morphologic transitions identified in the wax experiments will occur on Mars, Venus, and the Moon at extrusion rates $8.7,35$, and 113 times greater, respectively, than they would on Earth for the same lava rheology (Figure $7 b$ ). For a given extrusion rate the transitions are shifted to smaller viscosities when the gravity is reduced or cooling is enhanced. The results for submarine lavas [Griffiths and Fink, 1992] are included in Figure 7 for comparison.

From Figure 7 we conclude that an extrapolation of the laboratory results predicts that surface folding and "rifting" would be more common on Venus and the Moon than on subaerial terrestrial flows if extrusion rates, viscosities and vent temperatures are the same. By "more common", we mean that these surface structures are likely to occur closer to the vent or require less branching of the flow and thus should be found on large volume flows which are more likely to be preserved and observable by remote sensing techniques. However, all of the cases considered are extremely different from the submarine environment, in which rapid quenching is predicted to lead most commonly to "pillow" basalts and where only very large flow rates can produce "rifting" plate like crust or "folded" surfaces.

At flow rates greater than approximately $10^{-4} \mathrm{~m}^{3} \mathrm{~s}^{-1}$ the primary effect, if any, of solid crust on terrestrial subaerial basaltic flows is predicted to be limited to the formation of levees at the margins of the flow. The same should occur for extraterrestrial basalts but at flow rates greater than $10^{-2} \mathrm{~m}^{3} \mathrm{~s}^{-1}$. If vent temperatures are larger on Venus than on Earth as a consequence of a thinner and warmer planetary crust [Head and Wilson, 1986], then flow rates slightly smaller than this may give rise to broad smooth flows with no folding or rifting. Thus in all cases sufficiently rapid basalt eruptions are expected to produce broad plains of smooth lava. This is consistent with the occurrence of smooth lavas on both Venus and the Moon, although the relevant extrusion rates on these bodies are not known. The estimates for $\Psi$ can be used to find the distance from the vent at which
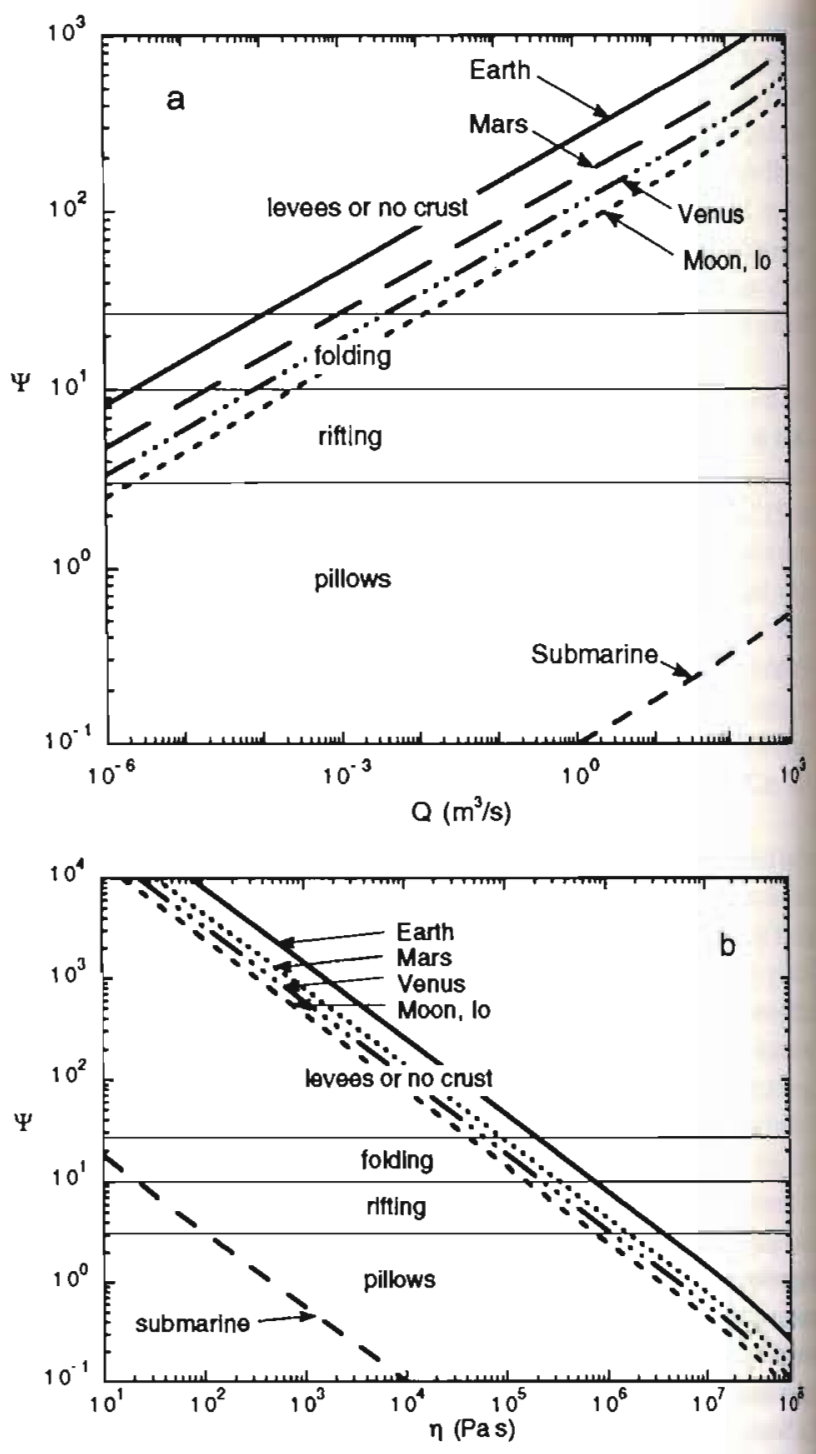

Fig. 7. Values of the dimensionless solidification time $\Psi$ for lava flows on Earth (subaerial), Mars, Venus, and the Moon, assuming a vent temperature of $1423 \mathrm{~K}$, a glass transition at $1003 \mathrm{~K}$, and $(a)$ a fixed magma viscosity at the vent of $\eta=10^{4} \mathrm{~Pa} s$ or $(b)$ a fixed extrusion rate of $Q=1 \mathrm{~m}^{3} \mathrm{~s}^{-1}$. Values for lo are the same as those for the Moon. The corresponding results for submarine lavas given by Griffiths and Fink [1992] are shown.

crust should begin to form: for example, forterrestrial flows spreading radially on a flat plane with a constant extrusion rate $Q \sim 10^{4} \mathrm{~m}^{3} \mathrm{~s}^{-1}$ (a small value for flood basalt eruptions) and a viscosity $\eta-10^{2}$ Pas we calculate from ( 3 ) and ( $7 a) \Psi \approx 8 \times 10^{4}$. The corresponding depth scale from (5) is $H \approx 2.5 \mathrm{~m}$. For this example the solidification time $t_{s} \approx 125$ $s$ (found earlier) implies that the surface will solidify at a distance (8a) of the order of $D_{s} \approx 710 \mathrm{~m}$ from the vent. For the same eruption on Venus solid crust would begin to form after $57 \mathrm{~s}$ and at a distance of about $470 \mathrm{~m}$ from the vent. The corresponding solidification distances for the same eruption on Mars and the Moon are $670 \mathrm{~m}$ and $620 \mathrm{~m}$, respectively. The large distances obtained in this example serve to demonstrate the relatively small role played by crust on such rapid, low-viscosity flows. They also show that solidification begins closest to the vent on Venus, farthest away on Earth. The calculation has not taken into account possible differences in vent temperature or the effects of channelization of the flow, which will cause magma to travel farther before developing a crust. 
In the absence of quenching by water the "pillow" regime $(\Psi<3)$ is predicted to occur only at very small effusion rates or large viscosities ( $\eta>10^{6} Q$ in SI units). Thus the high-viscosity silicic lava domes of Earth, and similar "pancake" structures discovered on Venus [Head et al., 1991] might be interpreted as very large individual pillows. Like the smaller low-viscosity basalt pillows, the silicic domes enlarge at least partly by endogenous inflation. Although their dimensions are roughly in proportion to the viscosity of the extruded melt, the size of silicic domes tends to be determined by the volume of melt available, whereas the size of basalt pillows is that at which the pillow breaks off from the feeding tube or its skin fractures and a new pillow begins to develop.

For most extraterrestrial lavas, we know neither the composition (and hence viscosity) nor the eruption rate, so that calculations of the types presented in the previous section give inconclusive results. This is the same dilemma shared by all previous attempts to estimate eruption conditions of lunar and martian flows [e.g., Hulme, 1976; Zimbelman, 1985; Cattermole, 1987]. Most of these studies invoke empirical relationships between effusion rates and rheologic properties of terrestrial lavas [e.g., Hulme, 1976], or they make ad hoc assumptions about strain rates or emplacement durations [e.g., Fink, 1980; Theilig and Greeley, 1986]. Nevertheless it is worthwhile to see whether or not our approach gives results consistent with the previous studies. To do this we must first assign a value of $\Psi$ to an observed flow, based on its morphology. Relation (7) can then be rearranged to provide the flow rate as a function of magma viscosity:

Axisymmetric

$$
\begin{gathered}
Q=(\eta / g \Delta \rho)^{3}\left(\Psi / t_{s}\right)^{4}, \\
q=(\eta / g \Delta \rho)^{2}\left(\Psi / t_{s}\right)^{3} .
\end{gathered}
$$

As an example, consider a leveed flow from Ascraeus Mons that has surface folds near its terminus [Zimbelman, 1985](Figure 4). The flow is channelled in one direction between two levees. Hence the line source scaling $(9 b)$ is appropriate, and the desired flow rate in the channel is one half the calculated vent flux $q$ since values of $\Psi$ at morphologic transitions are found for spreading from both sides of line sources. If we consider this flow to have had conditions close to those at the boundary between levees and folding, then $\Psi \approx 25$ $( \pm 20 \%)$. If we also assume that the magma had andesitic composition ( $\left.\eta=10^{6} \mathrm{~Pa} \mathrm{~s}\right)$, then $(9 b)$, the Martian parameters of Table 1, and a channel width of $800 \mathrm{~m}$ indicate a vent flux of $\sim 2.4 \times 10^{4} \mathrm{~m}^{3} \mathrm{~s}^{-1}$. This is much larger than the flux of $24 \mathrm{~m}^{3} \mathrm{~s}^{-1}$ obtained by Zimbelman [1985] using a critical Graetz number. However, $(9 b)$ shows that the same morphology could occur for Zimbleman's flux if the viscosity were as small as $3 \times 10^{4} \mathrm{~Pa}$ s.

Where compositional information is available, as for several locations on the moon, classification of flow morphology may allow the eruption rates to be constrained. Perhaps the most exciting application of this approach will come with return of data from the Mars Observer mission in 1993 [Albee and Palluconi, 1990]. The Mars Observer camera will obtain images with spatial resolution of up to $2 \mathrm{~m}$ per pixel, exposing much greater morphologic detail than has previously been seen for extraterrestrial flows. A second instrument on Mars Observer, the thermal emission spectrometer, will provide spectral data which under ideal conditions may permit lava flow composition to be positively identified. This combination of information, in conjunction with the results of our modeling, may offer the best constraints yet on the effusion rates and eruption durations of extra-terrestrial lavas.

\section{ConClusions}

An extrapolation from the behavior of spreading wax under cold water in the laboratory to convective and radiative cooling of lavas under a variety of environmental conditions is successful in predicting the extreme differences between submarine pillow basalts and rapid subaerial eruptions of high-temperature basalts. Under intermediate conditions, several morphological transitions can occur in the wax analog that can be seen on terrestrial lava flows. These results provide a means of inferring information about the extrusion rates or rheologies of inaccessible planetary and lunar lava flows. Additional testing and more precise calibration on terrestrial lava flows is required. This testing can be achieved only through further comparison with observed lava morphologies, matched with more precise estimates of effusion rates and magma viscosities in individual flows.

Our main purposes here were to compare the model predictions with the morphology of some terrestrial lava flows for which the rheology and effusion rate are reasonably well constrained and to estimate the effects of the different planetary environments on surface morphology. The surface cooling calculations and scaling for lateral gravity-driven flow indicate that differences will result primarily from different gravitational accelerations and, for lavas on Venus, from the additional cooling by atmospheric convection. Cooling of the surface of submarine lavas is much more rapid than in all other environments and the flow is more strongly influenced by its solid crust (R.W. Griffiths, and J.H. Fink, Effects of solidifying crust on the advance of lava flows and domes, submitted to Journal of Fluid Mechanics, 1992). If the morphological sequence found in the laboratory experiments proves relevant to lavas, a number of general results follow. The two independent parameters, effusion rate and magma viscosity, are not separable when working from remote observations of lava flow morphology alone. However, if the magma composition and rheology are determined by other means, lower limits can be placed on the effusion rates that are able to produce broad sheetlike flows having smooth surfaces or leveed channels. "Pillow" morphology will occur only on flows having very large viscosity, very small extrusion rates, or on flows quenched by water.

Acknowledgments. The authors are grateful for Nathan Bridges' assistance in compiling some of the physical parameters for lavas and their environments and for helpful reviews by Jim Zimbelman and an anonymous referee. Thanks also to Richard Enright for taking the videos of active basalt flows at Kilauea. Research was supported by NASA grant NAGW 529 from the Planetary Geology and Geophysics Program, National Science Foundation grant EAR 9018216, and a visiting fellowship from The Australian National University.

\section{REFERENCES}

Albee, A.L., and D.F. Palluconi, Mars Observer's global mapping mission, Eos, Trans. AGU, 71, 1099-1107, 1990.

Anderson, S.W., and J.H. Fink, The development and distribution of surface textures at the Mount St. Helens dome, in Lava Flows and Domes: Emplacement Mechanisms and Hazard Implications, edited by J.H. Fink, IAVCEI Proc. Volcanol., 2, pp. 25-46, Springer Verlag, New York, 1990.

Anderson, S.W., and J.H. Fink, Crease structures: Indicators of emplacement rates and surface stress regimes of lava flows. Geol. Soc. Am. Bull., 104, 615-625, 1992.

Arndt, N.T., A.J. Naldrett, and D.R. Pyke, Komatiitic and iron rich tholeiitic lavas of Munro Township, Northeast Ontario, J. Petrol., 18, 319-369, 1977.

Carslaw, H.S., and J.C. Jaeger, Conduction of Heat in Solids, 2nd Ed., 510pp. Oxford University Press, New York, 1959.

Cattermole, P., Sequence, rheological properties, and effusion rates of volcanic flows at Alba Patera, Mars, Proc. Lunar Planet. Sci. Conf. 17th, Part 2, J. Geophys. Res., 92, suppl., E553-E560, 1987.

Chadwick, W.W. Jr., R.J. Archuleta, and D.A. Swanson, The mechanics of ground deformation precursory to dome-building extrusions at Mount St. Helens, 1981-1982, J. Geophys. Res., 93, 4351-4366, 1988.

Fink, J.H., Surface folding and viscosity of rhyolite flows, Geology, 8, 250$254,1980$. 
Fink, J.H., and R.C. Fletcher, Ropy pahoehoe: Surface folding of a viscous fluid, J. Volcanol. Geotherm. Res., 4, 151-170, 1978.

Fink, J.H., and R.W. Griffiths, Radial spreading of viscous-gravity currents with solidifying crust, J. Fluid Mech., 221, 485-509, 1990.

Fink, J.H., and R.W. Griffiths, A laboratory analog study of the morphology of lava flows extruded from point and line sources, J. Volcanol. Geotherm. Res., in press, 1992.

Griffiths, R.W. and J.H. Fink, Solidification and morphology of submarine lavas: A dependence on extrusion rate, J. Geophys. Res., in press, 1992.

Head, J.W., and L. Wilson, Volcanic processes and landforms on Venus: Theory, predictions and observations, J. Geophys. Res., 91, 9407-9446, 1986.

Head, J.W., D.B. Campbell, C. Elachi, J.E. Guest, D.P. McKenzie, R.S. Saunders, G.C. Schaber, and G. Schubert, Venus volcanism: Initial analysis from Magellan data, Science, 252, 276-288, 1991.

Hulme, G., The interpretation of lava flow morphology, Geophys. $J . R$. Astron. Soc., 39, 361-383, 1974.

Hulme, G., The determination of rheological properties and effusion rate of an Olympus Mons lava, Icarus, 27, 207-213, 1976.

Huppert, H.E., and R.S.J. Sparks, Melting the roof of a chamber containing a hot turbulently convecting fluid, J. Fluid Mech., 188, 107-131, 1988.

Huppert, H.E., J.B. Shepherd, H. Sigurdsson, and R.S.J. Sparks, On lava dome growth, with application to the 1979 lava extrusion of the Soufriere of St. Vincent, J. Volcanol. Geotherm. Res., 14, 199-222, 1982.

Kieffer, H.H., T.Z. Martin, A.R. Peterfreund, B.M. Jakosky, E.D. Miner, and F.D. Palluconi, Thermal and albedo mapping of Mars during the Viking Primary Mission, J. Geophys. Res., 82, 4249-4291, 1977.

Kirkpatrick, R.J., Kinetics of crystallization of igneous rock, Rev. Mineral., 8, 321-398, 1981.

Lipman, P.W., and N.G. Banks, Aa Flow Dynamics, Mauna Loa 1984, in Volcanism in Hawaii, edited by R.W. Decker, T.L. Wright, and P.H. Stauffer, U.S. Geol. Surv. Prof. Pap. 1350, 1527-1567, 1987.

Moore, H.J., Preliminary estimate of rheologic properties of 1984 Mauna Loa lava, in Volcanism in Hawaii, edited by R.W. Decker, T.L. Wright, and P.H. Stauffer, U.S. Geol. Surv. Prof. Pap. 1350, 1569-1588, 1987.

Murase, T., and A.R. McBirney, Properties of some common igneous rocks and their melts at high temperatures, Geol. Soc. Am. Bull., 84,3563-3592, 1973.

Murase, T., A.R. McBirney, and W.G. Melson, Viscosity of the dome of Mount St. Helens, J. Volcanol. Geotherm. Res., 24, 193-204, 1985.

Nisbet, E.G., N.J. Bickle, and A. Martin, The mafic and ultramafic lavas of the Belingwe Greenstone Belt, Rhodesia, J. Petrol., 18, 521-566, 1977.

Pinkerton, H., Factors affecting the morphology of lava flows, Endeavour, 11, 73-79, 1987.

Pinkerton, H., and R.S.J. Sparks, The 1975 sub-terminal lavas, Mount Etna: A case history of the formation of a compound lava field, J. Volcanol. Geotherm. Res., 1, 167-182, 1976.
Pinkerton, H., and R.S.J. Sparks, Fieid measurements of the rheology of lava, Nature, 276, 383-385, 1978.

Ryan, M.P., and C.G. Sammis, The glass transition in basalt, J. Geophys. Res., 86, 9516-9539, 1981.

Shaw, H.R., Rheology of basalt in the melting range, J. Petrol., 10, 510-535, 1969.

Shaw, H.R., and D.A. Swanson, Eruption and flow rates of flood basalts, in Proceedings of Second Columbia River Basalt Symposium, pp. 271-299, Eastern Washington State College Press, Cheney,WA, 1970.

Swanson, D.A., and R.T. Holcomb, Regularities in growth of the Mount St. Helens dacite dome, 1980-1986, in Lava Flows and Domes: Emplacement Mechanisms and Hazard Implications, edited by J.H. Fink, IAVCEI Proc. Volcanol., 2, pp. 1-24, Springer Verlag, New York, 1990.

Swanson, D.A., D. Dzurisin, R.T. Holcomb, E.Y. Iwatsubo, W.W.Chadwick, Jr, T.J. Casadevall, J.W. Ewert, and C.C. Heliker, Growth of the lava dome at Mount St. Helens, WA, in The emplacement of silicic domes and lava flows, edited by J.H. Fink, Spec. Pap. Geol. Soc. Am., 212, pp. 1-16, 1987.

Theilig, E., and R. Greeley, Lava flows on Mars: Analysis of small surface features and comparisons with terrestrial analogs, Proc. Lun. Planet. Sci. Conf. 17th, Part 1, J. Geophys. Res., 91, suppl., E193-E206, 1986.

Turcotte, D.L., and G. Schubert, Geodynamics, 450 pp., John Wiley, New York, 1982.

Turner, J.S., Buoyancy Effects in Fluids, 368 pp., Cambridge University Press, New York, 1973.

Uhlmann, D.R., and L.C. Klein, Crystallization kinetics, viscous flow, and thermal histories of lunar breccias 15286 and 15498, Proc. Lunar Planet. Sci. Conf., 7th, 2529-2541, 1976.

Uhlmann, D.R., P.K.I. Onorato, and G.W. Scherer, A simplified model for glass formation, Proc. Lunar Planet. Sci. Conf., 10th, 375-381, 1979.

Westrich, H.R., H.W. Stockman, and J.C. Eichelberger, Degassing of rhyolitic magma during ascent and emplacement, J. Geophys. Res., 93, 6503$6511,1988$.

Wilson, L., and J.W. Head, A comparison of volcanic eruption processes on Earth, Moon, Mars, Io, and Venus, Nature, 302, 663-669, 1983.

Zimbelman, J.R., Estimates of rheologic properties for flows on the martian volcano Ascraeus Mons, Proc. Lunar Planet. Sci. Conf. 16th, Part 1, J. Geophys. Res., 90, suppl., D157-D162, 1985.

J.H. Fink, Geology Department, Arizona State University, Tempe, AZ 85287-1404.

R.W. Griffiths, Research School of Earth Sciences, Australian National University, GPO Box 4, Canberra ACT 2601, Australia.

(Received March 2, 1992; revised August 7, 1992; accepted August 17, 1992.) 